\title{
Prevalence and risk factors of prolonged corrected QT interval in general Chinese population
}

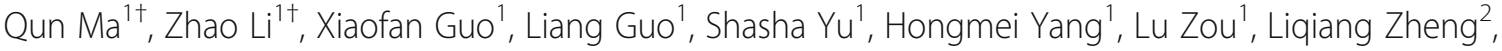 \\ Guowei Pan ${ }^{3}$, Yonghong Zhang ${ }^{4}$ and Yingxian Sun ${ }^{1^{*}}$ (I)
}

\begin{abstract}
Background: Corrected QT (QTC) interval has been correlated with total and CVD mortality. Although much is known about the relation between prolonged QTc interval and clinical outcome, there is no information on the prevalence and specific risk factors of QTc prolongation in general Chinese population. We evaluated the prevalence of prolonged QTc interval and its risk factors in general Chinese population, aiming to fill in the gaps in the literature and provide evidence for potential CVD risk prediction and disease burden estimate in community.

Methods: A population-based survey was conducted on 11,209 participants over the age of 35 in rural areas of Liaoning Province from 2012 to 2013. Twelve-lead ECGs and automatic analysis were performed on all participants. Logistic regression adjustments were made by using the Bazett's formula to correlate specific risk factors with prolonged QTc intervals (> $440 \mathrm{~ms}$ ) for potential confounders.

Results: The overall prevalence of prolonged QTc interval was 31.6\%. The prevalence increased significantly with age (24.1\% among those aged 35-44 years; $28.3 \%, 45-54$ years; 35.2\%, 55-64 years; $43.4 \%, \geq 65$ years, $P<0.001)$. Participants with a history of CVD had a higher prevalence of QTc prolongation (40.7\% vs. $30.0 \%)$. In the fully adjusted logistic regress model, older age, abdominal obesity, hypertension, diabetes, hypokalemia and any medicine used in the past two weeks were associated independently with increased risk for prolonged QTc interval (All $P<0.05$ ). We found no significant differences between general obesity, hypocalcemia and hypomagnesemia with prolongation of QTc interval. Female sex showed opposite results after applying clinical diagnostic criteria, and high physical activity could reduce the risk of prolonged QTc interval.

Conclusions: The prevalence of prolonged QTc interval was relatively high in general Chinese population and listed relevant factors, which would help identify patients at risk in pre-clinical prevention and provide evidence for estimating potential CVD burden and making management strategies in community.
\end{abstract}

Keywords: Long QT syndrome, Prevalence, Risk factors

\section{Background}

The QT interval on the surface electrocardiogram (ECG) indicates the duration from the beginning of ventricular depolarization to the end of ventricular repolarization. Prolonged heart rate-corrected QT (QTc) interval has been correlated with many adverse cardiovascular

\footnotetext{
* Correspondence: yxsun@mail.cmu.edu.cn

${ }^{+}$Qun Ma and Zhao Li contributed equally to this work.

'Department of Cardiology, the First Hospital of China Medical University,

155 Nanjing North Street, Heping District, Shenyang 110001, People's

Republic of China

Full list of author information is available at the end of the article
}

outcomes including arrhythmia [1], coronary heart disease [2, 3], sudden death [4] and mortality [5]. Since ECG is a noninvasive and simple test, prolonged QTc interval can be used as a rapid objective method for targeting the population with high CVD risk in clinical practice.

The prevalence of prolonged QTc interval has already been reported in patients with different diseases, such as diabetes $(25.6 \%$ vs. $7.6 \%$, type 1 diabetes vs. control) [6, 7], HIV infection (19.8\%) [8] and coronary heart disease (17.2\%) [9], from hospital settings. There is limited

(c) The Author(s). 2019 Open Access This article is distributed under the terms of the Creative Commons Attribution 4.0 International License (http://creativecommons.org/licenses/by/4.0/), which permits unrestricted use, distribution, and reproduction in any medium, provided you give appropriate credit to the original author(s) and the source, provide a link to the Creative Commons license, and indicate if changes were made. The Creative Commons Public Domain Dedication waiver (http://creativecommons.org/publicdomain/zero/1.0/) applies to the data made available in this article, unless otherwise stated. 
information on the prevalence of QTc interval prolongation in general populations. According to the Third National Health and Nutrition Examination Survey (NHANES III), there were 270 and 259 of 4053 men and 4314 women, respectively, had QTc interval prolongation between 1988 and 1994 [10].

Prolonged QTc interval is a result of a complex interplay between genetic and environmental factors [11, 12]. As rapid changes of the pattern of cardiometabolic disease and lifestyle habits, the prevalence and specific risk factors of prolonged QTc interval might be different from decades ago. However, no study has described the epidemiology of QTc interval prolongation in general population from China, recent or not. Using a large, contemporary general Chinese population, we evaluated the prevalence of QTc interval prolongation and its risk factors, aiming to fill in the gaps in the literature and provide evidence for potential CVD risk prediction and disease burden estimate in community.

\section{Methods}

\section{Study population}

Methods of this study has already been published elsewhere [13]. A representative population aged $\geq 35$ years was chosen to exhibit the prevalence of cardiovascular risk factors from January 2012 to August 2013 in rural areas of Liaoning Province, which is situated in the northeast of China. The study used a stratified multistage cluster sampling method. In the first phase, three counties (Dawa, Liaoyang, and Zhangwu County) were chosen from the eastern, northern and southern parts of Liaoning province. In the second phase, we selected randomly a town from each county (a total of 3 towns). In the third phase, 8-10 rural villages were selected randomly from each town (a total of 26 rural villages). And this study excluded participants with pregnancy, malignant tumor and mental disorder. All qualified permanent residents aged above 35 years in each village were invited to participate in the research (a total of 14,016 participants). Among those participants, 11,956 participants agreed and completed the research And the response rate was $85.3 \%$. This study was reviewed and approved by the Ethics Committee of China Medical University (Shenyang, China). All procedures were carried out according to the ethics committee standards. All participants' written consent should be obtained after they had been told and explained about the objectives, benefits, medical items and confidentiality agreement of personal information. Besides, the Ethics Committee has also approved to include the illiterate population. And we have obtained the written consent of all participants themselves or their authorized proxies. We used the baseline data in this report and only participants with complete research information were included, which making a final sample size of 11,209 (5106 males and 6103 females).

\section{Data collection and measurements}

Data collection, measurement methods and the questionnaires of this study have already been published and described previously [14-16]. Cardiologists and trained nurses collected the primary data at a single clinic visit by using standard questionnaires through face-to-face interviews. We invited all qualified investigators to participate in organized training before the investigation. The training content included the purpose of this study, how to conduct questionnaires, the standard measurement methods, the importance of standardization, and the research procedures. After this training, we evaluated a rigorous test, and only those who got a perfect score in the test could become an investigator. Our inspectors received further instructions and support during the data collection process. And there was a central steering committee and a quality control subcommittee to monitor study progress at different stages.

Data of demographic characteristics, family income, lifestyle risk factors, history of heart disease and any medicine used in the past two weeks were obtained through standardized questionnaire interviews. Educational level was classified into 3 groups: primary school or below, middle school and high school or above. Family income was divided into 3 groups: $\leq 5000,5000-20$, 000 and $>20,000 \mathrm{CNY} /$ year. Physical activity was divided into occupational physical activity and leisure physical activity. A detailed description of the method has ever been described elsewhere [17]. Occupational and leisure physical activities were combined and reclassified into three categories: (1) low: reported subjects with mild occupational and leisure physical activity; (2) moderate: reported subjects with moderate or high levels of occupational or leisure physical activity; (3) high: reported subjects with moderate or high levels of occupational and leisure physical activity.

According to the American Heart Association proto$\mathrm{col}$, after at least $5 \mathrm{~min}$ of rest, blood pressure (BP) was measured three times every 2 min using a standardized automatic electronic sphygmomanometer (HEM-907; Omron), which had been verified according to the protocol of British Hypertension Society [18]. The participants were told to avoid exercise and caffeinated beverages for at least $30 \mathrm{~min}$ before the measurement. During the measurement, the participants sat with the arm supported at the same height of the heart. The average of the three BP values was calculated and used for further analysis.

Height and weight were measured to the nearest 0.1 $\mathrm{cm}$ and $0.1 \mathrm{~kg}$, respectively. During this period, the participants wore lightweight clothes and no shoes. Body 
mass index (BMI) was calculated as body weight in kilograms divided by the square of the body height in meters. Waist circumference (WC) was measured at the level of umbilicus with inelastic tapeline (accurate to 0.1 $\mathrm{cm}$ ), during which the participants stood at the end of normal expiration.

Fasting blood samples were collected in the morning after all participants had fasted for at least $12 \mathrm{~h}$. All blood samples were taken from the antecubital vein by using a BD Vacutainer tube containing EDTA (Becton, Dickinson and Co., Franklin Lakes, NJ, USA). The serum was then separated from whole blood through the centrifuge, and the serum samples were frozen at $-20^{\circ} \mathrm{C}$ for further tests in a certified central laboratory. Total cholesterol (TC), triglyceride (TG), low-density lipoprotein cholesterol (LDL-C), high-density lipoprotein cholesterol (HDL-C), serum potassium, serum calcium, serum magnesium, fasting plasma glucose (FPG), and other routine blood biochemical indexes were analyzed by enzymatic method using an automatic analyzer (Olympus AU640 Auto-Analyzer; Olympus Corp., Kobe, Japan). In addition, all laboratory devices have been calibrated and samples were duplicated by blind method.

A MAC 5500 (GE Healthcare; Little Chalfont, Buckinghamshire, UK) was used by well-trained cardiologists to perform a 12-lead ECGs (rest 10s) for all participants and the results was analyzed automatically through the MUSE Cardiology Information System, version 7.0.0 (GE Healthcare). And Bazett's formula was then used to correct QT intervals for heart rate [19].

\section{Definitions}

Hypertension was defined as $\mathrm{SBP} \geq 140 \mathrm{mmHg}$ and/or $\mathrm{DBP} \geq 90 \mathrm{mmHg}$ and/or use of antihypertensive medicines according to the JNC-7 report [20]. According to the recommendations from experts of the WHO for Asians, general obesity was defined as $B M I \geq 28 \mathrm{~kg} / \mathrm{m}^{2}$ [21]. Abdominal obesity was defined as $W C \geq 102 \mathrm{~cm}$ for men and $W C \geq 88 \mathrm{~cm}$ for women [22]. Dyslipidemia was diagnosed according to the criteria established by $\mathrm{Na}$ tional Cholesterol Education Program-Third Adult Treatment Panel (ATP III) [23]: TC $\geq 6.21 \mathrm{mmol} / \mathrm{L}$ (240 $\mathrm{mg} / \mathrm{dL}$ ) for high $\mathrm{TC}, \mathrm{TG} \geq 2.26 \mathrm{mmol} / \mathrm{L}(200 \mathrm{mg} / \mathrm{dL})$ for high TG, LDL-C $\geq 4.16 \mathrm{mmol} / \mathrm{L} \quad(160 \mathrm{mg} / \mathrm{dL})$ for high LDL-C and HDL-C $<1.03 \mathrm{mmol} / \mathrm{L}(40 \mathrm{mg} / \mathrm{dL})$ for low HDL-C. Diabetes mellitus was defined according to the WHO criteria [24]: $\mathrm{FPG} \geq 7 \mathrm{mmol} / \mathrm{L}(126 \mathrm{mg} / \mathrm{dL})$ and/or receiving diabetes treatment. According to recognized criteria, the QT interval corrected by the Bazett's formula was considered to have been prolonged if it exceeds $440 \mathrm{~ms}$ [25], and we set $450 \mathrm{~ms}$ for men and 470 $\mathrm{ms}$ for women to further adjust gender for specific prolonged QTc interval.

\section{Statistical analysis}

Descriptive statistics of all study variables had been calculated, including categorical variables (expressed as numbers and ratios) and continuous variables (expressed as mean values and standard deviations). Non-parameter test or an appropriate $\mathrm{x}^{2}$-test were used to evaluate the differences among these categories. Multivariate logistic regression analysis was adopted to calculate the possible risk factors (age, gender, race, family income, physical activity, education, current smoking status, current drinking status, obesity, hypertension, diabetes, high TC, high TG, high LDL-C, low HDL-C, serum electrolytes and medication) for QTc interval prolongation with odds ratios (ORs) and corresponding 95\% confidence intervals (CIs). All statistical analyses were conducted using SPSS version 23.0 software, and $P$ values less than 0.05 were considered as statistically significant.

\section{Results}

\section{Baseline characteristics of study population}

The present study included 5106 males and 6103 females, with an average age of 54 (SD 11) years. Table 1 lists the differences of characteristics in research population based on QTc grouping. Older participants were more likely to have prolonged QTc interval (>440 ms). A significantly lower proportion of prolonged QTc interval was observed among males. Participants with prolonged QTc interval had higher levels of cardiometabolic indexes such as SBP, DBP, TC, TG, LDL-C and FPG (all $P<0.05$ ), while current smokers or drinkers were more common among those participants with normal QTc interval.

\section{Prevalence of prolonged QTc interval}

Table 2 shows the distribution of QTc interval according to age and sex. The overall prevalence of QTc prolongation was 31.6\%. The mean QTc interval was significantly longer among females than males $(436.1 \pm 23.5$ vs. $422.1 \pm 24.2 \mathrm{~ms}$, respectively, $P<$ 0.001, Fig. 1), which was observed across all the age groups. The prevalence of prolonged QTc interval was significantly correlated with age $(24.1 \%$ in the $35-44$ age group; $28.3 \%$ in the $45-54$ age group; $35.2 \%$ in the $55-64$ age group; $43.4 \%$ in the $\geq 65$ age group, $P<0.001)$. The prevalence of QTc interval prolongation was also significantly higher among female participants in all four age groups. While after adjusting specific prolonged QTc interval for sex, this result reverse. Figure 2 shows the prevalence of prolonged QTc interval in different clinical comorbidities. A relatively higher prevalence was observed among those participants with either of the major comorbidities, including hypertension, diabetes, dyslipidemia, general and abdominal obesity (all $P<0.001$ ). In 
Table 1 Differences of characteristics in study population based on QTC grouping $(N=11,209)$

\begin{tabular}{|c|c|c|c|}
\hline Variables & $\mathrm{QTc} \leq 440 \mathrm{~ms}(n=7666)$ & QTc $>440 \mathrm{~ms}(n=3543)$ & $P$-value \\
\hline Age (year) & $53 \pm 10$ & $56 \pm 11$ & $<0.001^{*}$ \\
\hline Male gender & $4063(53.0)$ & $1043(29.4)$ & $<0.001^{*}$ \\
\hline Race of Han & 7250 (94.6) & $3380(95.4)$ & 0.066 \\
\hline Current smoking status & 2915 (38.0) & $1028(29.0)$ & $<0.001^{*}$ \\
\hline Current drinking status & $1981(25.8)$ & $520(14.7)$ & $<0.001^{*}$ \\
\hline Education & & & $<0.001^{*}$ \\
\hline Primary school or below & $3603(47.0)$ & $1987(56.1)$ & \\
\hline Middle school & $3326(43.4)$ & $1254(35.4)$ & \\
\hline High school or above & 737 (9.6) & $302(8.5)$ & \\
\hline Physical activity & & & $<0.001^{*}$ \\
\hline Low & $2013(26.3)$ & $1278(36.1)$ & \\
\hline Moderate & $5210(68.0)$ & 2076 (58.6) & \\
\hline High & $443(5.8)$ & $189(5.3)$ & \\
\hline Family income (CNY/year) & & & $<0.001^{*}$ \\
\hline$\leq 5000$ & $876(11.4)$ & $513(14.5)$ & \\
\hline $5000-20,000$ & $4179(54.5)$ & $1952(55.1)$ & \\
\hline$>20,000$ & $2611(34.1)$ & $1078(30.4)$ & \\
\hline SBP $(\mathrm{mmHg})$ & $138.9 \pm 22.1$ & $148.0 \pm 25.2$ & $<0.001^{*}$ \\
\hline $\mathrm{DBP}(\mathrm{mmHg})$ & $80.9 \pm 11.1$ & $84.4 \pm 12.7$ & $<0.001^{*}$ \\
\hline BMI $\left(\mathrm{kg} / \mathrm{m}^{2}\right)$ & $24.6 \pm 3.6$ & $25.2 \pm 3.8$ & $<0.001^{*}$ \\
\hline WC $(\mathrm{cm})$ & $81.9 \pm 9.7$ & $83.6 \pm 9.9$ & $<0.001^{*}$ \\
\hline $\mathrm{TC}(\mathrm{mmol} / \mathrm{L})$ & $5.2 \pm 1.1$ & $5.4 \pm 1.2$ & $<0.001^{*}$ \\
\hline TG $(\mathrm{mmol} / \mathrm{L})$ & $1.6 \pm 1.4$ & $1.8 \pm 1.7$ & $<0.001^{*}$ \\
\hline LDL-C (mmol/L) & $2.9 \pm 0.8$ & $3.0 \pm 0.9$ & $<0.001^{*}$ \\
\hline $\mathrm{HDL}-\mathrm{C}(\mathrm{mmol} / \mathrm{L})$ & $1.4 \pm 0.4$ & $1.4 \pm 0.4$ & $0.014^{*}$ \\
\hline $\mathrm{FPG}(\mathrm{mmol} / \mathrm{L})$ & $5.8 \pm 1.4$ & $6.2 \pm 2.1$ & $<0.001^{*}$ \\
\hline Calcium (mmol/L) & $2.3 \pm 0.1$ & $2.3 \pm 0.1$ & $<0.001^{*}$ \\
\hline Potassium (mmol/L) & $4.2 \pm 0.3$ & $4.1 \pm 0.4$ & $<0.001^{*}$ \\
\hline Magnesium (mmol/L) & $0.8 \pm 0.1$ & $0.8 \pm 0.1$ & 0.119 \\
\hline History of heart disease ${ }^{a}$ & $647(8.4)$ & $451(12.7)$ & $<0.001^{*}$ \\
\hline Medication used ${ }^{\mathrm{b}}$ & 3806 (49.6) & $2122(59.9)$ & $<0.001^{*}$ \\
\hline
\end{tabular}

Data are expressed as the mean \pm SD or as $\mathrm{n}(\%)$

Abbreviations: BMI, body mass index; CNY, China Yuan (1CNY = 0.15 USD); DBP, diastolic blood pressure; FPG, fasting plasma glucose; HDL-C, high-density lipoprotein cholesterol; LDL-C, low-density lipoprotein cholesterol; QTC, corrected QT; SBP, systolic blood pressure; TC, total cholesterol; TG, triglyceride; WC, waist circumference

${ }^{*} P<0.05$ for the significance of difference of variables between prolonged QTc interval and QTc $\leq 440 \mathrm{~ms}$.

ancluding coronary heart disease, arrythmia and heart failure

${ }^{b}$ Indicating any self-reported medication used in the past two weeks

addition, the prevalence of prolonged QTc interval was higher among the participants with CVD history ( $40.7 \%$ vs. $30.0 \%, 671 / 1650$ vs. $2871 / 9559$ ).

\section{Factors associated with prolonged QTc interval}

Table 3 shows the multivariable logistic regression analysis of risk factors associated with prolonged QTc interval. The risk of prolonged QTc interval increased by $22.8 \%$ for every 10 years of age (OR: $1.228,95 \% \mathrm{CI}: 1.168$ to $1.290, P<0.001)$. Prolonged QTc interval $(\mathrm{QTc}>440$ $\mathrm{ms}$ ) was found in 1043 (29.3\%) and 2500 (70.6\%) of male and female, which is showed in Table 1. Compared with males, the risk of females QTc interval prolongation increased about 3 times (OR: 2.878 , 95\%CI: 2.564 to 3.229 , $P<0.001)$. Participants with hypertension and diabetes had increased by 83.8 and $59.3 \%$ risks respectively for prolonged QTc interval (OR: 1.838, 95\%CI: 1.675 to 2.016; OR: $1.593,95 \% \mathrm{CI}$ : 1.391 to 1.824 respectively, 
Table 2 Distribution of QTC interval in the included population by age and sex

\begin{tabular}{|c|c|c|c|c|c|c|c|}
\hline \multirow{2}{*}{$\begin{array}{l}\text { Age } \\
\text { (year) }\end{array}$} & \multirow{2}{*}{$\begin{array}{l}\text { Sample } \\
\text { size }\end{array}$} & \multicolumn{2}{|c|}{ Mean QTc (ms) } & \multicolumn{2}{|c|}{ Prevalence of prolonged QTC } & \multicolumn{2}{|c|}{ Prevalence of prolonged QTc adjusted for sex } \\
\hline & & Male & Female & Male & Female & Male> 450 & Female $>470$ \\
\hline $35-44$ & 2699 & $415.4 \pm 21.7$ & $431.6 \pm 23.2$ & $149(12.6)$ & $502(33.0)$ & $80(6.8)$ & $62(4.1)$ \\
\hline $45-54$ & 3481 & $419.3 \pm 23.3$ & $434.4 \pm 22.1$ & $256(16.7)$ & $730(37.5)$ & $140(9.1)$ & $106(5.4)$ \\
\hline $55-64$ & 3371 & $424.7 \pm 24.6$ & $438.6 \pm 23.6$ & $358(22.9)$ & $829(45.8)$ & $191(12.2)$ & $135(7.5)$ \\
\hline$\geq 65$ & 1658 & $431.8 \pm 24.5$ & $443.3 \pm 24.5$ & 280 (33.5) & $439(53.3)$ & $180(21.6)$ & $92(11.2)$ \\
\hline
\end{tabular}

Data are expressed as the mean \pm SD or as $n(\%)$

Abbreviations: QTc, corrected QT

both $P<0.001$ ). Abdominal obesity, high TG and low potassium level were also significantly associated with prolonged QTc interval, which increased by 15.6, 24.1 and $163.6 \%$ risks respectively for prolonged QTc interval (OR: $1.156,95 \% \mathrm{CI}: 1.010$ to $1.324, P=0.035$; OR: $1.241,95 \% \mathrm{CI}: 1.104$ to $1.395, P<0.001$; OR: 2.636, 95\%CI: 1.806 to $3.846, P<0.001)$. Recent use of any medication achieved statistical significance for 13.1\% higher risk of prolonged QTc interval (OR: 1.131, 95\%CI: 1.036 to $1.234, P=0.006)$. To further eliminate the interference of self-reported medication use, we performed a sensitivity analysis excluding the participants on medication (Table 4). Age, female sex, abdominal obesity, hypertension, diabetes and hypokalemia were still risk factors for prolonged QTc interval, except for high TG. Specifically, the risk increased by $21.6 \%$ for every 10 years of age (OR: 1.216 , 95\%CI: 1.127 to $1.311, P<0.001)$. And female sex, abdominal obesity, hypertension, diabetes and hypokalemia increased by $199.5,26.4,93.3,85.6$ and $122.4 \%$ respectively (OR: $2.995,95 \%$ CI: 2.502 to 3.584 , $P<0.001$; OR: $1.264,95 \%$ CI: 1.019 to $1.567, P=0.033$; OR: $1.933,95 \%$ CI: 1.680 to $2.224, P<0.001$; OR: 1.856, 95\%CI: 1.469 to $2.346, P<0.001$; OR: 2.224 , 95\%CI: 1.118 to $4.426, P=0.023)$. Furthermore, compared to low physical activity, high physical activity reduced to $70.2 \%$ risk for prolonged QTc interval (OR: $0.702,95 \%$ CI: 0.525 to $0.939, P=0.017$ ). While after setting $450 \mathrm{~ms}$ for men and $470 \mathrm{~ms}$ for women, which is the clinical diagnosis criteria for long QT syndrome (Prolonged QTc interval was found in 591 (59.9\%) and 395 (40.1\%) of male and female), female sex might be a protective factor among those population, which the risk reduced to 49.7\% (OR: 0.497, 95\%CI: 0.416 to $0.594, P<0.001)$ in Table 5. And high physical activity remained a protective factor for reducing the risk to $65.2 \%$ (OR: $0.652,95 \% \mathrm{CI}: 0.462$ to $0.921, P=0.015$ ).

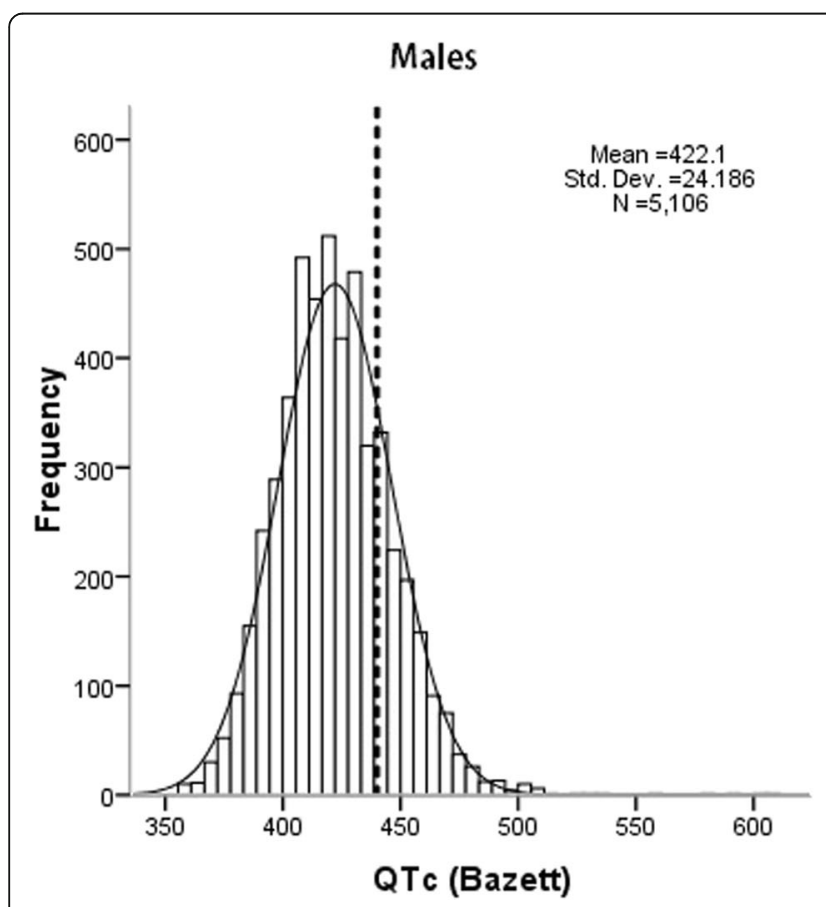

Fig. 1 Distribution of QTC interval of the population by sex

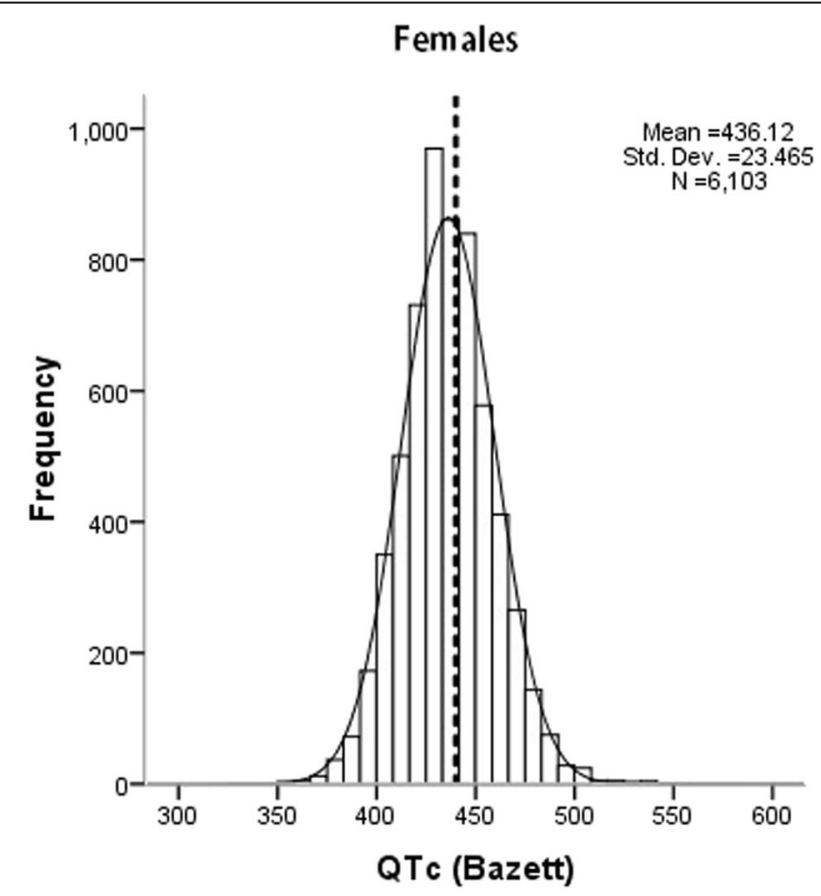




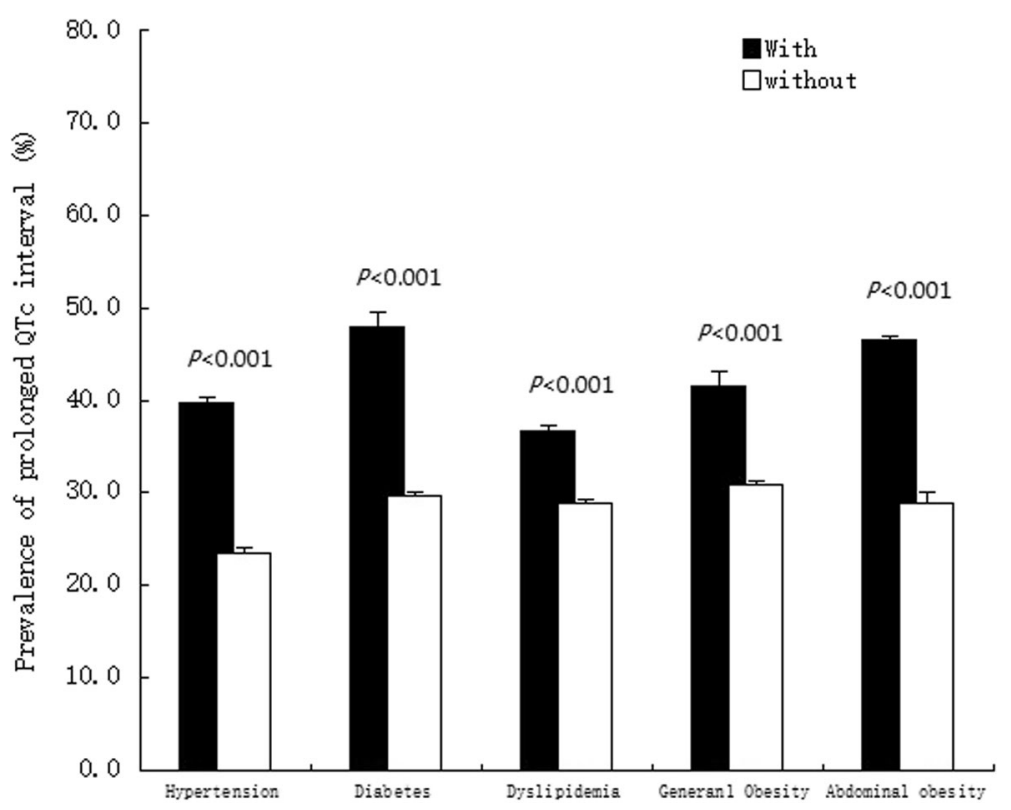

Fig. 2 Prevalence of prolonged QTc interval with and without major clinical comorbidities

\section{Discussion}

In the present study, we reported a relatively higher prevalence of prolonged QTc interval in general Chinese population compared to Hawaii. We found age, abdominal obesity, hypertension, diabetes, hypokalemia and any medicine used in the past two weeks were associated with increased risk for prolongation of QTc interval.

We found the overall prevalence of QTc prolongation was $31.6 \%$, by a $440 \mathrm{~ms}$ cut-point for definition using Bazett's formula, which is the most common method for heart rate adjustment [26]. In a rural Hawaiian population, the prevalence of prolonged QTc interval was found to be $21.2 \%$, using the same criteria [27]. Compared with the baseline characteristics of long QTc interval from a Japanese cohort, the prevalence of which were around $7.5 \%$ among males men and $16.5 \%$ among females [28], our prevalence were much higher (20.4\% for men and $41 \%$ for women). In subgroup analyses, the prevalence among patients with diabetes was also higher than that observed in previous studies using similar criteria $[7,29,30]$. Regional and racial differences might contribute to the inconsistent results. Since the patterns of cardiometabolic diseases and lifestyle factors have important influence on the prevalence, the conducted year of the study might also contribute to the discrepancies. Prolonged QTc interval was closely related to increased risks of total death, cardiovascular death, coronary heart disease death, and sudden cardiac death [26]. Therefore, the high prevalence we observed in general Chinese population indicated a potential large burden of CVD prevention in rural China.
We confirmed the impacts of age, diabetes and hypertension on prolonged QTc interval which were consistent with previous findings $[6,8,27,29,31]$. As for gender, female sex of the borderline groups $(440 \mathrm{~ms}<$ QTc $<450 \mathrm{~ms}$ for males and $440 \mathrm{~ms}<$ QTc $<470 \mathrm{~ms}$ for females) were more likely to develop long QT syndrome (QTc > $450 \mathrm{~ms}$ for males and QTc > $470 \mathrm{~ms}$ for females), which leads to female as a risk factor after setting 440 ms for prolonged QTc interval. Furthermore, after using the clinical diagnosis criteria for long QT syndrome to exclude borderline population, we found female seems to be less likely for long QT syndrome in the population. Although the results were inconsistent, it's certain that sex hormones might modulate ventricular repolarization and partly attributed to the sex-specific difference on QTc interval, which indicating female seems to have higher QTc interval compared to male among the borderline population [32-34]. The presence of hypertension and diabetes could lead to significant higher risks for prolonged QTc interval, indicating that a screening ECG should be warranted before prescribing medications in these populations.

It has been shown that general obesity is correlated with prolonged QTc interval [35-37]. However, we failed to find a significant correlation between general obesity and prolonged QTc interval. Although the prevalence was higher among participants with general obesity, there was no association observed in multivariable models, which was consistent with previous findings [10, 29]. In contrast, abdominal obesity was an independent risk factor for prolonged QTc, suggesting that visceral 
Table 3 Multivariate logistic regression analyses of prolonged QTc interval and associated factors

\begin{tabular}{llll}
\hline Variables & ORs & $95 \%$ Cls & $P$-value \\
\hline Age (per 10 year increase) & 1.228 & $1.168-1.290$ & $<0.001^{*}$ \\
Female gender & 2.878 & $2.564-3.229$ & $<0.001^{*}$ \\
Race of Han ${ }^{\mathrm{a}}$ & 1.196 & $0.981-1.458$ & 0.076 \\
Current smoking status & 1.075 & $0.970-1.191$ & 0.166 \\
Current drinking status & 0.938 & $0.821-1.071$ & 0.344
\end{tabular}

Education

\begin{tabular}{llrl} 
Primary school or below & \multicolumn{1}{l}{1.000 (reference) } & \\
Middle school & 1.075 & $0.974-1.186$ & 0.151 \\
High school or above & 1.157 & $0.986-1.357$ & 0.073
\end{tabular}

Physical activity

Low

Moderate

High

Family income (CNY/year)

$$
\leq 5000
$$

$5000-20,000$

$>20,000$

General obesity

Abdominal obesity

Hypertension

Diabetes

High TC

High TG

High LDL-C

Low HDL-C

Calcium $(\mathrm{mmol} / \mathrm{L})<1.875$

Potassium $(\mathrm{mmol} / \mathrm{L})<3.5$

Magnesium $(\mathrm{mmol} / \mathrm{L})<0.7$

History of heart disease ${ }^{b}$

Medication used

\subsection{0 (reference)}

$\begin{array}{lll}0.925 & 0.840-1.018 & 0.11 \\ 0.832 & 0.685-1.011 & 0.064\end{array}$

1.000 (reference)

\begin{tabular}{lll}
0.931 & $0.815-1.064$ & 0.294 \\
0.926 & $0.799-1.072$ & 0.302 \\
1.043 & $0.916-1.187$ & 0.528 \\
1.156 & $1.010-1.324$ & $0.035^{*}$ \\
1.838 & $1.675-2.016$ & $<0.001^{*}$ \\
1.593 & $1.391-1.824$ & $<0.001^{*}$ \\
0.977 & $0.847-1.127$ & 0.747 \\
1.241 & $1.104-1.395$ & $0.001^{*}$ \\
1.112 & $0.919-1.347$ & 0.276 \\
1.119 & $0.980-1.278$ & 0.096 \\
0.667 & $0.178-2.497$ & 0.547 \\
2.636 & $1.806-3.846$ & $<0.001^{*}$ \\
0.746 & $0.200-2.789$ & 0.664 \\
1.065 & $0.927-1.223$ & 0.375 \\
1.131 & $1.036-1.234$ & $0.006^{*}$ \\
\hline
\end{tabular}

${ }^{*} \mathrm{P}<0.05$ for the independent association between prolonged QTC interval and each factor after adjusting for the remaining factors

Abbreviations: CNY, China Yuan (1CNY $=0.15$ USD); HDL-C, high-density lipoprotein cholesterol; LDL-C, low-density lipoprotein cholesterol; TC, total cholesterol; TG, triglyceride; OR, odds ratio; QTc, corrected QT; $95 \% \mathrm{Cl}, 95 \%$ confidence interval

${ }^{a}$ Compared with other ethnic minorities in China, such as Mongol and Manchu bIncluding coronary heart disease, arrythmia and heart failure

Indicating any self-reported medication used in the past two weeks

obesity played a more important role in the obesityrelated risk and prolongation of QTc. We also found a significant correlation between high TG and prolonged QTc interval in the data set including medication use, but not in sensitivity analysis. More researches are expected to confirm this relationship.

The strength of the present study was that we for the first time provided a detailed epidemiologic description
Table 4 Sensitivity analysis of prolonged QTc interval and associated factors after exclusion of participants on medication in the past two weeks in multiple logistic regression $(n=5281)$

\begin{tabular}{llll}
\hline Variables & ORs & $95 \%$ Cls & $P$-value \\
\hline Age (per 10 year increase) & 1.216 & $1.127-1.311$ & $<0.001^{*}$ \\
Female gender & 2.995 & $2.502-3.584$ & $<0.001^{*}$ \\
Race of Han ${ }^{\mathrm{a}}$ & 1.260 & $0.944-1.682$ & 0.117 \\
Current smoking status & 0.948 & $0.808-1.112$ & 0.511 \\
Current drinking status & 1.020 & $0.842-1.237$ & 0.836
\end{tabular}

Education

Primary school or below 1.000 (reference)

$\begin{array}{llll}\text { Middle school } & 1.086 & 0.936-1.261 & 0.276 \\ \text { High school or above } & 1.294 & 1.029-1.626 & 0.027^{*}\end{array}$

Physical activity

Low 1.000 (reference)

$\begin{array}{llll}\text { Moderate } & 0.879 & 0.756-1.023 & 0.096 \\ \text { High } & 0.702 & 0.525-0.939 & 0.017^{*}\end{array}$

Family income (CNY/year)

$$
\leq 5000
$$

$5000-20,000$

$>20,000$

General obesity

Abdominal obesity

Hypertension

Diabetes

High TC

1.000 (reference)

High TG

High LDL-C

Low HDL-C

$1.024 \quad 0.824-1.273$

0.828

1.105

$0.876-1.393$

0.401

$1.089 \quad 0.891-1.330 \quad 0.407$

$1.264 \quad 1.019-1.567 \quad 0.033^{*}$

$1.933 \quad 1.680-2.224<0.001^{*}$

$1.856 \quad 1.469-2.346<0.001^{*}$

$0.987 \quad 0.793-1.229 \quad 0.909$

$\begin{array}{lll}1.172 & 0.973-1.413 & 0.094\end{array}$

$1.142 \quad 0.843-1.547 \quad 0.391$

Calcium $(\mathrm{mmol} / \mathrm{L})<1.875 \quad 0.603 \quad 0.071-5.106 \quad 0.642$

Potassium $(\mathrm{mmol} / \mathrm{L})<3.5 \quad 2.224 \quad 1.118-4.426 \quad 0.023^{*}$

$\begin{array}{llll}\text { Magnesium }(\mathrm{mmol} / \mathrm{L})<0.7 & 1.893 & 0.323-11.098 & 0.479\end{array}$

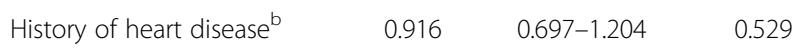

*P $<0.05$ for the independent association between prolonged QTC interval and each factor after adjusting for the remaining factors

Abbreviations: CNY, China Yuan (1CNY = 0.15 USD); HDL-C, high-density lipoprotein cholesterol; LDL-C, low-density lipoprotein cholesterol; TC, total cholesterol; TG, triglyceride; OR, odds ratio; QTc, corrected QT; $95 \% \mathrm{Cl}$, 95\% confidence interval

${ }^{a}$ Compared with other ethnic minorities in China, such as Mongol and Manchu Including coronary heart disease, arrythmia and heart failure

of prolonged QTc interval in a general population from China with a large sample size and reflects the differences of the prevalence among hypertension, diabetes, dyslipidemia, general obesity and abdominal obesity. Our study had some limitations that need to be considered. First, instead of using sex-specific tertiles for QTc interval, we chose $440 \mathrm{~ms}$ as the definition for prolonged QTc interval for both sexes to include all borderline subgroups, and we set $450 \mathrm{~ms}$ for men and $470 \mathrm{~ms}$ for 
Table 5 Multivariate logistic regression analyses of prolonged QTc interval and associated factors after adjusting the clinical diagnosis criteria for gender

\begin{tabular}{|c|c|c|c|}
\hline Variables & ORs & $95 \% \mathrm{Cls}$ & $P$-value \\
\hline Age (per 10 year increase) & 1.257 & $1.164-1.357$ & $<0.001^{*}$ \\
\hline Female gender & 0.497 & $0.416-0.594$ & $<0.001^{*}$ \\
\hline Race of $\operatorname{Han}^{\mathrm{a}}$ & 0.827 & $0.617-1.109$ & 0.205 \\
\hline Current smoking status & 1.015 & $0.870-1.184$ & 0.847 \\
\hline Current drinking status & 1.085 & $0.905-1.300$ & 0.379 \\
\hline \multicolumn{4}{|l|}{ Education } \\
\hline Primary school or below & \multicolumn{3}{|c|}{1.000 (reference) } \\
\hline Middle school & 1.010 & $0.862-1.184$ & 0.900 \\
\hline High school or above & 1.014 & $0.784-1.312$ & 0.916 \\
\hline \multicolumn{4}{|l|}{ Physical activity } \\
\hline Low & \multicolumn{3}{|c|}{1.000 (reference) } \\
\hline Moderate & 0.896 & $0.768-1.046$ & 0.164 \\
\hline High & 0.652 & $0.462-0.921$ & $0.015^{*}$ \\
\hline \multicolumn{4}{|l|}{ Family income (CNY/year) } \\
\hline$\leq 5000$ & \multicolumn{3}{|c|}{1.000 (reference) } \\
\hline $5000-20,000$ & 0.883 & $0.728-1.073$ & 0.211 \\
\hline$>20,000$ & 0.848 & $0.680-1.059$ & 0.146 \\
\hline General obesity & 1.097 & $0.842-1.430$ & 0.493 \\
\hline Abdominal obesity & 1.191 & $0.950-1.493$ & 0.130 \\
\hline Hypertension & 2.357 & $2.001-2.775$ & $<0.001^{*}$ \\
\hline Diabetes & 1.638 & $1.362-1.970$ & $<0.001^{*}$ \\
\hline High TC & 0.865 & $0.689-1.087$ & 0.214 \\
\hline High TG & 1.231 & $1.033-1.467$ & $0.020^{*}$ \\
\hline High LDL-C & 1.111 & $0.826-1.495$ & 0.486 \\
\hline Low HDL-C & 1.143 & $0.937-1.394$ & 0.187 \\
\hline Calcium $(\mathrm{mmol} / \mathrm{L})<1.875$ & 0.830 & $0.103-6.713$ & 0.861 \\
\hline Potassium $(\mathrm{mmol} / \mathrm{L})<3.5$ & 1.957 & $1.230-3.114$ & $0.005^{*}$ \\
\hline Magnesium $(\mathrm{mmol} / \mathrm{L})<0.7$ & 0.590 & $0.072-4.860$ & 0.624 \\
\hline History of heart disease ${ }^{b}$ & 1.375 & $1.126-1.678$ & $0.002^{*}$ \\
\hline Medication used ${ }^{c}$ & 1.253 & $1.085-1.448$ & $0.002^{*}$ \\
\hline
\end{tabular}

*P $<0.05$ for the independent association between prolonged QTc interval and each factor after adjusting for the remaining factors

Abbreviations: QTc, corrected QT; OR, odds ratio; $95 \% \mathrm{Cl}$, 95\% confidence interval; CNY, China Yuan (1CNY=0.15 USD);

$\mathrm{TC}$, total cholesterol; TG, triglyceride; LDL-C, low-density lipoprotein cholesterol; HDL-C, high-density lipoprotein cholesterol

${ }^{a}$ Compared with other ethnic minorities in China, such as Mongol and Manchu

bIncluding coronary heart disease, arrythmia and heart failure

Indicating any self-reported medication used in the past two weeks

women to identify specific long QT syndrome. Besides, we used automatically measured QTc values and Bazett's formula to further analysis. A pooled analysis found that long QTc interval was significantly associated with total and CVD mortality, using $440 \mathrm{~ms}$ as the cut-point for the highest category for both sexes in most of the included studies [26]. Our goal was to capture the risk factors of those participants at even slightly elevated risk. Second, although we adjusted most crucial confounders such as serum electrolytes, there were still other factors, including cardiomyopathy, cirrhosis and genetic determinants, that were not accounted for in this study. And for the physical activity, it is contradictory to interpret high physical activity means protective factor for prolongation of QTc among Tables 3, 4, 5. There is no declared specific recommended physical activity for longQTc subjects, and some intense physical activities could lead to sudden cardiac death $[38,39]$. In general, although it seemed that high physical activity is a protective factor for prolongation of QTc among this population, it may also lead to some occurrences of sudden cardiac death. Besides, this study did not obtain specific monitoring data on physical activity. However, the self-administered questionnaire we collected strengthened the results. Another concern was the medicine history of the participants. We failed to obtain the specific information on QT-prolonging drugs. However, the medication used in the past two weeks we collected included QT-prolonging drugs as well as many other drugs that could also cause prolonged QTc interval, such as antibiotics and some Chinese traditional medicines, which strengthened the results. On the other hand, the result of our sensitivity analysis excluding participants on medication was consistent. Furthermore, our results were based on cross-sectional design, so no causal relationship could be established.

\section{Conclusions}

We found the prevalence of QTc interval prolongation is higher in the general Chinese population, especially those with CVD history. Older age, female sex, abdominal obesity, hypertension, diabetes and hypokalemia were associated with increased risks of prolonged QTc interval. This finding would help identify patients at risk in pre-clinical prevention and provide evidence for estimating potential CVD burden and making management strategies for rural Chinese population.

\section{Abbreviations \\ BMI: Body mass index; BP: Blood pressure; Cls: Confidence intervals; CVD: Cardiovascular disease; ECG: Electrocardiogram; FPG: Fasting plasma glucose; HDL-C: High-density lipoprotein cholesterol; LDL-C: Low-density lipoprotein cholesterol; ORs: Odds ratios; QTc: Bazett's corrected QT; TC: Total cholesterol; TG: Triglyceride; WC: Waist circumference}

\section{Acknowledgements}

The authors thank the efforts of the project team members.

\section{Authors' contributions}

The research design were formulated by YS and ZL. The study was carried out by $Z L, X G, L G, S Y, H Y, L u Z, L i Z, G P$, and $Y Z$. Data analysis was carried out by $\mathrm{QM}, \mathrm{ZL}$ and $\mathrm{XG}$. The article was written by $\mathrm{QM}$, with editing by $\mathrm{XG}, \mathrm{ZL}$. $\mathrm{QM}, \mathrm{ZL}$ and YS had primary responsibility for final content. All authors read and approved the final manuscript. 


\section{Funding}

This study was supported by grants from the "Twelfth Five-Year" project funds (National Science and Technology Support Program of China, Grant No. 2012BAJ18B02). The funders had no role in the study design, data collection and analysis, the decision to publish or the preparation of the manuscript.

\section{Availability of data and materials}

The data used and/or analysed during the current research are available. from the corresponding author on reasonable request.

\section{Ethics approval and consent to participate}

The study was approved by the Ethics Committee of China Medical University (Shenyang, China). All procedures were performed in accordance with the ethical standards. Written consent was obtained from all participants after they had been informed of the objectives, benefits, medical items and confidentiality agreement of personal information. Besides, the Ethics Committee has also approved to include the illiterate population. And we obtained the written informed consents from all the participants or the proxies authorized by the project participants themselves.

\section{Consent for publication}

Not applicable.

\section{Competing interests}

None.

\section{Author details}

'Department of Cardiology, the First Hospital of China Medical University, 155 Nanjing North Street, Heping District, Shenyang 110001, People's Republic of China. 'Department of Clinical Epidemiology, Library, Shengjing Hospital of China Medical University, Shenyang, Liaoning, People's Republic of China. ${ }^{3}$ Department of Prevention of Chronic Non-communicable Diseases, Center for Disease Prevention and Control of Liaoning Province, Shenyang, Liaoning, People's Republic of China. ${ }^{4}$ Department of Epidemiology, School of Public Health, Medical College of Soochow University, Suzhou, Jiangsu, People's Republic of China.

\section{Received: 7 October 2018 Accepted: 6 November 2019}

\section{Published online: 29 November 2019}

\section{References}

1. Ahnve S, Lundman T, Shoaleh-var M. The relationship between QT interval and ventricular arrhythmias in acute myocardial infarction. Acta medica Scandinavica. 1978;204:17-9.

2. Crow RS, Hannan PJ, Folsom AR. Prognostic significance of corrected QT and corrected JT interval for incident coronary heart disease in a genera population sample stratified by presence or absence of wide QRS complex: the ARIC study with 13 years of follow-up. Circulation. 1985-1989;2003:108. https://doi.org/10.1161/01.cir.0000095027.28753.9d

3. Lee JM, Yoo KD, Oh YS, Kim DB, Park CS, Jang SW, Kim JH, Ihm SH, Kim HY, Lee MY, et al. Relationship between resting electrocardiographic parameters and estimated 10-year risk for coronary heart disease in healthy adults in the USA. Annals of noninvasive electrocardiology : the official journal of the International Society for Holter and Noninvasive Electrocardiology, Inc. 2010; 15:315-20. https://doi.org/10.1111/j.1542-474X.2010.00386.x

4. Straus SM, Kors JA, De Bruin ML, van der Hooft CS, Hofman A, Heeringa J, Deckers JW, Kingma JH, Sturkenboom MC, Stricker BH, et al. Prolonged QTC interval and risk of sudden cardiac death in a population of older adults. J Am Coll Cardiol. 2006;47:362-7. https://doi.org/10.1016/j.jacc.2005.08.067

5. de Bruyne MC, Hoes AW, Kors JA, Hofman A, van Bemmel JH, Grobbee DE. Prolonged QT interval predicts cardiac and all-cause mortality in the elderly. The Rotterdam study. Eur Heart J. 1999;20:278-84.

6. Sivieri R, Veglio M, Chinaglia A, Scaglione P, Cavallo-Perin P. Prevalence of QT prolongation in a type 1 diabetic population and its association with autonomic neuropathy. The neuropathy study Group of the Italian Society for the study of diabetes. Diabetic medicine : a journal of the British Diabetic Association. 1993;10:920-4

7. Veglio M, Bruno G, Borra M, Macchia G, Bargero G, D'Errico N, Pagano GF, Cavallo-Perin P. Prevalence of increased QT interval duration and dispersion in type 2 diabetic patients and its relationship with coronary heart disease: a population-based cohort. J Intern Med. 2002;251:317-24.

8. Reinsch N, Buhr C, Krings P, Kaelsch H, Neuhaus K, Wieneke H, Erbel R, Neumann T. Prevalence and risk factors of prolonged QTc interval in HIVinfected patients: results of the HIV-HEART study. HIV clinical trials. 2009;10: 261-8. https://doi.org/10.1310/hct1004-261

9. Williams ES, Thomas KL, Broderick S, Shaw LK, Velazquez EJ, Al-Khatib SM, Daubert JP. Race and gender variation in the QT interval and its association with mortality in patients with coronary artery disease: results from the Duke databank for cardiovascular disease (DDCD). Am Heart J. 2012;164: 434-41. https://doi.org/10.1016/j.ahj.2012.05.024

10. Benoit SR, Mendelsohn AB, Nourjah P, Staffa JA, Graham DJ. Risk factors for prolonged QTC among US adults: third National Health and nutrition examination survey. European journal of cardiovascular prevention and rehabilitation: official journal of the European Society of Cardiology, Working Groups on Epidemiology \& Prevention and Cardiac Rehabilitation and Exercise Physiology. 2005;12:363-8.

11. Bednar MM, Harrigan EP, Anziano RJ, Camm AJ, Ruskin JN. The QT interval. Prog Cardiovasc Dis. 2001;43:1-45.

12. Wang Q, Chen Q, Towbin JA. Genetics, molecular mechanisms and management of long QT syndrome. Ann Med. 1998;30:58-65.

13. Yu S, Guo X, Yang H, Zheng L, Sun Y. An update on the prevalence of metabolic syndrome and its associated factors in rural Northeast China. BMC Public Health. 2014;14:877. https://doi.org/10.1186/14712458-14-877

14. Guo X, Li Z, Guo L, Zheng L, Yu S, Yang H, Zou L, Zhou Y, Zhang Y, Zhu L, et al. An update on overweight and obesity in rural Northeast China: from lifestyle risk factors to cardiometabolic comorbidities. BMC Public Health. 2014;14:1046. https://doi.org/10.1186/1471-2458-14-1046

15. Yu S, Sun Z, Zheng L, Guo X, Yang H, Sun Y. Prevalence of diabetes and impaired fasting glucose in hypertensive adults in rural China: far from leveling-off. Int J Environ Res Public Health. 2015;12:14764-79. https://doi. org/10.3390/ijerph121114764.

16. Guo X, Li Z, Guo L, Yu S, Yang H, Zheng L, Pan G, Zhang Y, Sun Y, Pletcher MJ. Effects of metabolically healthy and unhealthy obesity on prolongation of corrected QT interval. Am J Cardiol. 2017;119:1199-204. https://doi.org/ 10.1016/j.amjcard.2016.12.033

17. Hu G, Tuomilehto J, Silventoinen K, Barengo N, Jousilahti P. Joint effects of physical activity, body mass index, waist circumference and waist-to-hip ratio with the risk of cardiovascular disease among middle-aged Finnish men and women. Eur Heart J. 2004;25:2212-9. https://doi.org/10.1016/j.ehj. 2004.10.020.

18. O'Brien E, Petrie J, Littler W, de Swiet M, Padfield PL, O'Malley K, Jamieson M, Altman D, Bland M, Atkins N. The British hypertension society protocol for the evaluation of automated and semi-automated blood pressure measuring devices with special reference to ambulatory systems. J Hypertens. 1990;8:607-19.

19. Bazett HC. An analysis of the time relations of electrocardiograms. Heart. 1920:7:353-70.

20. Chobanian AV, Bakris GL, Black HR, Cushman WC, Green LA, Izzo JL Jr, Jones DW, Materson BJ, Oparil S, Wright JT Jr. The seventh report of the joint national committee on prevention, detection, evaluation, and treatment of high blood pressure: the JNC 7 report. Jama. 2003;289: 2560-71.

21. Organization, W.H. The Asia-Pacific perspective: redefining obesity and its treatment. Sydney: Health Communications Australia. 2000.

22. Organization, W.H. Diet, nutrition, and the prevention of chronic diseases: report of a joint WHO/FAO expert consultation. World Health Organization. 2003;916.

23. Executive Summary of The Third Report of The National Cholesterol Education Program (NCEP) Expert Panel on Detection, Evaluation, And Treatment of High Blood Cholesterol In Adults (Adult Treatment Panel III). Jama. 2001;285:2486-97

24. Organization, W.H. Definition and diagnosis of diabetes mellitus and intermediate hyperglycaemia: report of a WHO/IDF consultation. 2006.

25. Schwartz PJ, Moss AJ, Vincent GM, Crampton RS. Diagnostic criteria for the long QT syndrome. An update Circulation. 1993;88:782-4.

26. Zhang, Y.; Post, W.S.; Blasco-Colmenares, E.; Dalal, D.; Tomaselli, G.F.; Guallar, E. Electrocardiographic QT interval and mortality: a meta-analysis. Epidemiology (Cambridge, Mass.) 2011, 22, 660-670, doi:https://doi.org/10. 1097/EDE.0b013e318225768b 
27. Grandinetti A, Seifried S, Mor J, Chang HK, Theriault AG. Prevalence and risk factors for prolonged QTc in a multiethnic cohort in rural Hawaii. Clin Biochem. 2005;38:116-22. https://doi.org/10.1016/j.clinbiochem.2004.10.004 .

28. Maebuchi D, Arima H, Doi Y, Ninomiya T, Yonemoto K, Tanizaki Y, Kubo M, Hata J, Matsumura K, lida M, et al. QT interval prolongation and the risks of stroke and coronary heart disease in a general Japanese population: the Hisayama study. Hypertension research : official journal of the Japanese Society of Hypertension. 2010;33:916-21. https://doi.org/10.1038/hr.2010.88.

29. Li X, Ren H, Xu ZR, Liu YJ, Yang XP, Liu JQ. Prevalence and risk factors of prolonged QTc interval among Chinese patients with type 2 diabetes. Exp Diabetes Res. 2012;2012:234084. https://doi.org/10.1155/2012/234084

30. Brown DW, Giles WH, Greenlund KJ, Valdez R, Croft JB. Impaired fasting glucose, diabetes mellitus, and cardiovascular disease risk factors are associated with prolonged QTc duration. Results from the third National Health and nutrition examination survey. J Cardiovasc Risk. 2001:8:227-33.

31. Drici MD, Clement N. Is gender a risk factor for adverse drug reactions? The example of drug-induced long QT syndrome. Drug Saf. 2001;24:575-85.

32. Saba S, Link MS, Homoud MK, Wang PJ, Estes NA 3rd. Effect of low estrogen states in healthy women on dispersion of ventricular repolarization. Am J Cardiol. 2001;87:354-6 a359-310.

33. Gokce M, Karahan B, Yilmaz R, Orem C, Erdol C, Ozdemir S. Long term effects of hormone replacement therapy on heart rate variability, QT interval, QT dispersion and frequencies of arrhythmia. Int J Cardiol. 2005;99: 373-9. https://doi.org/10.1016/j.jjcard.2003.03.030 .

34. Haseroth K, Seyffart K, Wehling M, Christ M. Effects of progestin-estrogen replacement therapy on QT-dispersion in postmenopausal women. Int J Cardiol. 2000;75:161-5 discussion 165-166.

35. Esposito K, Marfella R, Gualdiero P, Carusone C, Pontillo A, Giugliano G, Nicoletti G, Giugliano D. Sympathovagal balance, nighttime blood pressure, and QT intervals in normotensive obese women. Obes Res. 2003;11:653-9. https://doi.org/10.1038/oby.2003.93 .

36. Papaioannou A, Michaloudis D, Fraidakis O, Petrou A, Chaniotaki F, Kanoupakis E, Stamatiou G, Melissas J, Askitopoulou H. Effects of weight loss on QT interval in morbidly obese patients. Obes Surg. 2003;13:869-73. https://doi.org/10.1381/096089203322618687

37. el-Gamal A, Gallagher D, Nawras A, Gandhi P, Gomez J, Allison DB, Steinberg JS, Shumacher D, Blank R, Heymsfield SB. Effects of obesity on QT, RR, and QTc intervals. Am J Cardiol. 1995;75:956-9.

38. Bika Lele EC, Pepouomi MN, Temfemo A, Mekoulou J, Assomo Ndemba P, Mandengue SH. Effect of intermittent variable intensity exercise on QT variation and risk of sudden cardiac death among Cameroonian school adolescents. Annales de cardiologie et d'angeiologie. 2018;67:48-53. https:// doi.org/10.1016/j.ancard.2017.03.003 .

39. Eijsvogels TM, Fernandez AB, Thompson PD. Are there deleterious cardiac effects of acute and chronic endurance exercise? Physiol Rev. 2016;96:99125. https://doi.org/10.1152/physrev.00029.2014 .

\section{Publisher's Note}

Springer Nature remains neutral with regard to jurisdictional claims in published maps and institutional affiliations.

\section{Ready to submit your research? Choose BMC and benefit from}

- fast, convenient online submission

- thorough peer review by experienced researchers in your field

- rapid publication on acceptance

- support for research data, including large and complex data types

- gold Open Access which fosters wider collaboration and increased citations

- maximum visibility for your research: over $100 \mathrm{M}$ website views per year

At BMC, research is always in progress.

Learn more biomedcentral.com/submissions 